\title{
ARTICLE
}

Received 19 Dec 2012 | Accepted 26 Feb 2013 | Published 16 Apr 2013 DOI: 10.1038/ncomms2664

\section{Intercalation and delamination of layered carbides and carbonitrides}

Olha Mashtalir ${ }^{1,2}$, Michael Naguib',2, Vadym N. Mochalin ${ }^{1,2}$, Yohan Dall'Agnese ${ }^{1,2}$, Min Heon ${ }^{1,2}$, Michel W. Barsoum ${ }^{1} \&$ Yury Gogotsi ${ }^{1,2}$

Intercalation and delamination of two-dimensional solids in many cases is a requisite step for exploiting their unique properties. Herein we report on the intercalation of two-dimensional $\mathrm{Ti}_{3} \mathrm{C}_{2}, \mathrm{Ti}_{3} \mathrm{CN}$ and $\mathrm{TiNbC}$-so called MXenes. Intercalation of hydrazine, and its co-intercalation with $\mathrm{N}, \mathrm{N}$-dimethylformamide, resulted in increases of the c-lattice parameters of surface functionalized $\mathrm{f}-\mathrm{Ti}_{3} \mathrm{C}_{2}$, from 19.5 to 25.48 and $26.8 \AA$, respectively. Urea is also intercalated into $\mathrm{f}-\mathrm{Ti}_{3} \mathrm{C}_{2}$. Molecular dynamics simulations suggest that a hydrazine monolayer intercalates between $\mathrm{f}-\mathrm{Ti}_{3} \mathrm{C}_{2}$ layers. Hydrazine is also intercalated into $\mathrm{f}-\mathrm{Ti}_{3} \mathrm{CN}$ and $\mathrm{f}-\mathrm{TiNbC}$. When dimethyl sulphoxide is intercalated into $\mathrm{f}-\mathrm{Ti}_{3} \mathrm{C}_{2}$, followed by sonication in water, the $\mathrm{f}-\mathrm{Ti}_{3} \mathrm{C}_{2}$ is delaminated forming a stable colloidal solution that is in turn filtered to produce MXene 'paper'. The latter shows excellent Li-ion capacity at extremely high charging rates.

\footnotetext{
${ }^{1}$ Department of Materials Science and Engineering, Drexel University, 3141 Chestnut Street, Philadelphia, Pennsylvania 19104, USA. ${ }^{2}$ A.J. Drexel Nanotechnology Institute, Drexel University, 3141 Chestnut Street, Philadelphia, Pennsylvania 19104, USA. Correspondence and requests for materials should be addressed to Y.G. (email: gogotsi@drexel.edu).
} 
A unique characteristic of layered materials is their ability to accommodate various ions and molecules between their layers, a phenomenon known as intercalation. Intercalation compounds of inorganic hosts (graphite, clays, di-chalcogenides and others) have also gained renewed interest owing to their unique chemical and physical properties ${ }^{1-6}$. De-intercalation of those compounds under certain conditions (such as thermal shock) as well as sonication or volume expansion reactions in the interlayer space lead to the formation of widely used exfoliated graphite g-11 $^{7}$ and two-dimensional (2D) materials with unusual electronic properties ${ }^{12-15}$.

Recently, a large family of 2D materials, labelled MXenesproduced by the extraction of the A-element from the layered ternary carbides, such as $\mathrm{Ti}_{3} \mathrm{AlC}_{2}$ and other MAX phases ${ }^{16}$, where $\mathrm{M}$ is an early transition metal, $\mathrm{A}$ is an $\mathrm{A}$ group element, and $\mathrm{X}$ is $\mathrm{C}$ or $\mathrm{N}$-was discovered ${ }^{17,18}$. The MXenes produced to date, viz., $\quad \mathrm{Ti}_{3} \mathrm{C}_{2}$ (ref. 17), $\mathrm{Ti}_{2} \mathrm{C}, \quad \mathrm{Ta}_{4} \mathrm{C}_{3}, \quad\left(\mathrm{Ti}_{0.5} \mathrm{Nb}_{0.5}\right)_{2} \mathrm{C}$, $\left(\mathrm{V}_{0.5} \mathrm{Cr}_{0.5}\right)_{3} \mathrm{C}_{2}$ and $\mathrm{Ti}_{3} \mathrm{CN}$ (ref. 18) are, in many aspects, graphene-like, forming stacks of sheets and scrolls. They also are good electrical conductors ${ }^{17-21}$ and are predicted to have high elastic moduli. ${ }^{22}$ Electrochemical intercalation of Li ions between the MXene sheets renders these solids promising materials for Liion battery anodes and hybrid electrochemical capacitors ${ }^{23-25}$. However, up to now there have been no reports of the chemical intercalation or large-scale delamination of MXenes or any other transition metal carbides.

It is important to note at the outset that the 2D MXene surfaces are not M-terminated, but covered with oxygen-containing groups, such as $\mathrm{OH}$, and fluorine (F) introduced after etching with aqueous hydrofluoric acid $(\mathrm{HF})^{17}$. The chemistry of exfoliated MXene produced by $\mathrm{HF}$ etching of $\mathrm{Ti}_{3} \mathrm{AlC}_{2}$ is much closer to $\mathrm{Ti}_{3} \mathrm{C}_{2}(\mathrm{OH})_{\mathrm{x}} \mathrm{O}_{\mathrm{y}} \mathrm{F}_{\mathrm{z}}$ than to the idealized structure of a pure carbide layer $\mathrm{Ti}_{3} \mathrm{C}_{2}$. Henceforth, and for brevity's sake, $\mathrm{f}-\mathrm{Ti}_{3} \mathrm{C}_{2}$ will be used instead of the more cumbersome $\mathrm{Ti}_{3} \mathrm{C}_{2}(\mathrm{OH})_{\mathrm{x}} \mathrm{O}_{\mathrm{y}} \mathrm{F}_{\mathrm{z}}$.

The original aim of this work was to reduce the $\mathrm{f}-\mathrm{Ti}_{3} \mathrm{C}_{2}$ surfaces to create Ti-terminated surfaces that theory predicts would be magnetic $^{25}$. A perusal of the graphene literature made it clear that hydrazine monohydrate $\mathrm{N}_{2} \mathrm{H}_{4} \cdot \mathrm{H}_{2} \mathrm{O}$ (HM) dissolved in $N, N$ dimethylformamide (DMF) is the reactant of choice ${ }^{26}$. Since in our case, HM was found to primarily act as an intercalant rather than a reducing agent, the research objectives were redirected towards intercalation and delamination of MXenes. Furthermore, as the layered structures of the MXenes retain some similarities to clays $^{17}$, we reviewed the intercalation chemistries of the latter. Numerous compounds, such as formamide and its derivatives, dimethyl sulphoxide (DMSO), urea and long-chain alkylamines, among others have been shown to intercalate clays ${ }^{27}$. For clays, HM is probably the most common intercalant; its intercalation results in the increase of kaolinite's $c$-lattice parameter $(c$-LP) from 7.2 to 10.3-10.4 A (refs 27-29).

Here we report, for the first time, on the intercalation of f- $\mathrm{Ti}_{3} \mathrm{C}_{2}$ with urea, HM, HM dissolved in DMF and DMSO. Importantly, intercalation of DMSO enabled us to delaminate stacked $\mathrm{f}-\mathrm{Ti}_{3} \mathrm{C}_{2}$ layers into separate $2 \mathrm{D}$ MXene sheets. We also show that $\mathrm{HM}$ intercalates $\mathrm{Ti}_{3} \mathrm{CN}$ and $\mathrm{TiNbC}$.

\section{Results}

Intercalation of MXenes. A schematic of MXene intercalation is shown in Fig. 1a. X-ray diffraction (XRD) showed that after intercalation with HM and/or DMF, the (0001) peaks were still present, but shifted to lower $2 \theta$ angles (Fig. $1 \mathrm{~b}, \mathrm{c}$ and Supplementary Fig. S1). Table 1 summarizes the $c$-LPs values for f- $\mathrm{Ti}_{3} \mathrm{C}_{2}$ treated with HM and HM in DMF. The initial $c$-LP was $19.5 \pm 0.1 \AA$, a value that does not change much with postintercalation drying (Table 1). After exposure to HM or HM in
DMF at $80^{\circ} \mathrm{C}$ for $24 \mathrm{~h}$, the $c$-LPs increased to $25.48 \pm 0.02$ and $26.8 \pm 0.1 \AA$, respectively. The larger $c$-LP increase in the latter case points to a synergistic effect when HM is dissolved in DMF before intercalation.

When the HM-intercalated powders were heated to $120^{\circ} \mathrm{C}$ in a vacuum oven, the $c$-LP decreased from $25.48 \pm 0.02$ to $20.6 \pm 0.3 \AA$, signifying that the intercalation process is essentially reversible. Heating powders intercalated with $\mathrm{HM}$ and DMF under the same conditions resulted in small increases in the $2 \theta$ angles (Fig. 1b-ii,c-ii). Thus, the HM/DMF combination is more resistant to de-intercalation than $\mathrm{HM}$ alone, possibly because of the higher boiling point of DMF $\left(153^{\circ} \mathrm{C}\right)$ compared with that of $\mathrm{HM}\left(114^{\circ} \mathrm{C}\right)$. However, when $\mathrm{f}-\mathrm{Ti}_{3} \mathrm{C}_{2}$ intercalated with $\mathrm{HM}$ and DMF was vacuum dried at $200^{\circ} \mathrm{C}$, the $c$-LP decreased to $20.1 \pm 0.5 \AA$.

X-ray photoelectron spectroscopy (XPS) (Supplementary Fig. S2) provides further evidence of intercalation. As previously reported ${ }^{17}$, exfoliated $\mathrm{f}-\mathrm{Ti}_{3} \mathrm{C}_{2}$ showed the presence of $\mathrm{Ti}-\mathrm{C}$ and $\mathrm{Ti}-\mathrm{O}$ bonds, as well as $\mathrm{OH}$ groups, suggested by the presence of a O1s peak around $532 \mathrm{eV}$ (see Supplementary Materials for more details). A N1s signal was also observed around $400 \mathrm{eV}$ in XPS spectra of $\mathrm{f}-\mathrm{Ti}_{3} \mathrm{C}_{2}$ treated with $\mathrm{HM}$ and $\mathrm{HM} / \mathrm{DMF}$ (insets in Supplementary Figs S2a,b, respectively). No nitrogen peaks were detected in $\mathrm{f}-\mathrm{Ti}_{3} \mathrm{C}_{2}$ before intercalation.

Scanning electron microscopy (SEM) images of $\mathrm{f}-\mathrm{Ti}_{3} \mathrm{C}_{2}$, before and after HM treatment in DMF at $80^{\circ} \mathrm{C}$ for $24 \mathrm{~h}$, shown in Fig. 2a,b, respectively, confirm that: (i) the MXene remains exfoliated after intercalation, and, (ii) the multilayers thicken (Fig. 2b) apparently by gluing individual monolayers together, forming 20-50-nm-thick lamellas. Note that the absence of XRD peaks corresponding to a $c$-LP of $19.5 \AA$ (Fig. $1 \mathrm{~b}$-i,c-i) implies that intercalation was essentially complete.

Transmission electron microscopy (TEM) images and corresponding selected area electron diffraction patterns of $\mathrm{f}-\mathrm{Ti}_{3} \mathrm{C}_{2}$ intercalated with $\mathrm{HM}$ in $\mathrm{DMF}$ at $80^{\circ} \mathrm{C}$ for $24 \mathrm{~h}$ (Fig. 2e,f) showed that the basal planes' hexagonal structure remains unchanged (compare inset in Fig. 2d with Fig. 2f) after intercalation ${ }^{17}$. The interplanar spacing in intercalated $\mathrm{f}-\mathrm{Ti}_{3} \mathrm{C}_{2}-$ $2.648 \AA$ for $(0 \overline{1} 10)$ and $1.540 \AA$ for $(0 \overline{2} 10)$-results in an $a$-LP of $3.057 \AA$, in excellent agreement with the $a$-LP of $\mathrm{f}-\mathrm{Ti}_{3} \mathrm{C}_{2}$ before intercalation and that of the $\mathrm{Ti}_{3} \mathrm{AlC}_{2}$, viz., $3.058 \AA^{17}$.

To demonstrate that intercalation is a general phenomenon rather than the exclusive property of $\mathrm{f}-\mathrm{Ti}_{3} \mathrm{C}_{2}$, the MXenes $\mathrm{Ti}_{3} \mathrm{CN}$ and TiNbC were also treated with HM. Similar to $f-\mathrm{Ti}_{3} \mathrm{C}_{2}$, the shift of the major XRD peak of these MXenes to lower $2 \theta$ values (Supplementary Fig. S3) confirmed their intercalation. It is thus reasonable to conclude that $\mathrm{f}$-MXenes-like other layered materials-can be readily intercalated by many different compounds.

In addition, the electrical resistivities of non-intercalated MXenes and MXenes treated with HM were measured. The resistivity values of all intercalated samples were higher than those of nonintercalated MXenes presumably owing to the increase of their $c$ LPs after intercalation (Supplementary Table S1). The differences in the magnitudes of the resistivity increases for different intercalated MXenes, at relatively the same expansion, can be partially explained by the different number of MXene atomic layers. In case of $\mathrm{M}_{3} \mathrm{X}_{2}$ (five atomic layers), the resistivity increases by an order of magnitude, whereas an increase by two orders is observed for the $\mathrm{M}_{2} \mathrm{C}$ (three atomic layers) compounds.

Molecular dynamics (MD) simulations. To further our understanding of the structure of intercalated MXene, $\mathrm{MD}$ simulations of $\mathrm{N}_{2} \mathrm{H}_{4}$ inserted between $\mathrm{OH}$-terminated $\mathrm{Ti}_{3} \mathrm{C}_{2}$ layers were carried out (Fig. 3a). MXene supercells $(4 \times 2 \times 1$ 
a
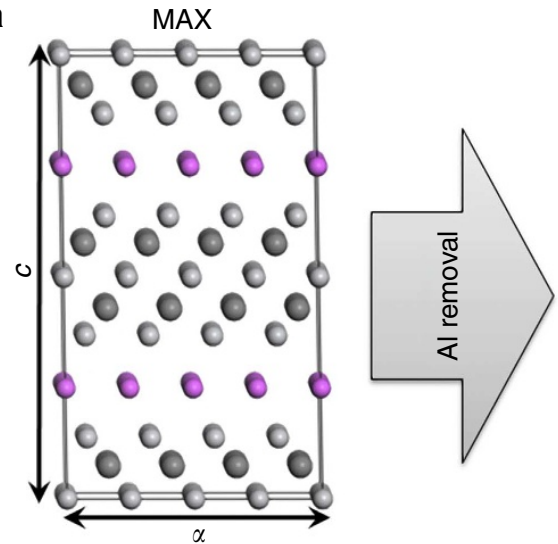

b

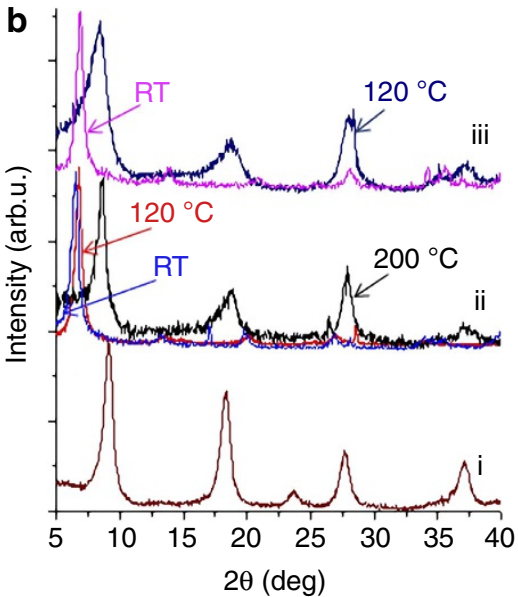

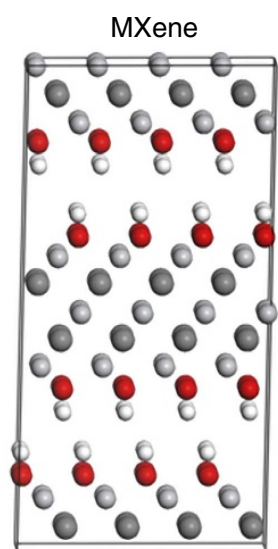

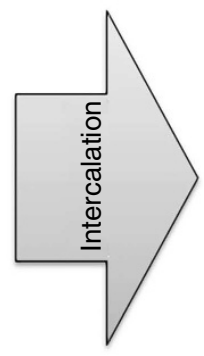

C

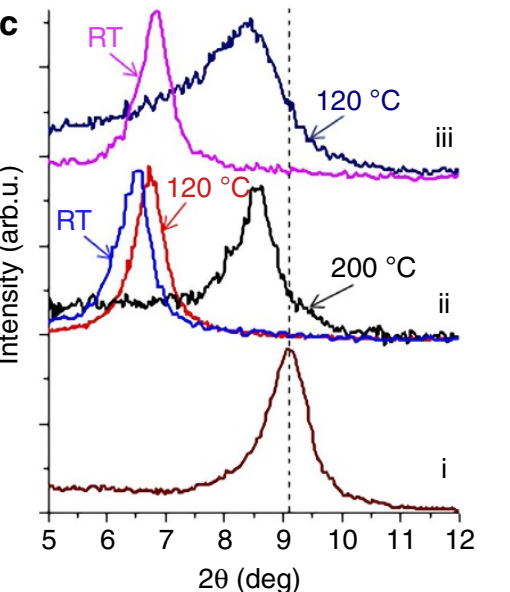

Intercalated MXene

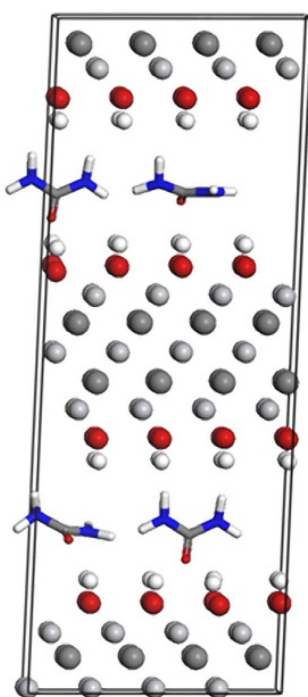

C
Ti
Al
$O$
$O \mathrm{~N}$
$\mathrm{OH}$

Figure 1 | Evidence of MXene intercalation. (a) Schematic of synthesis and intercalation of $\mathrm{f}-\mathrm{Ti}_{3} \mathrm{C}_{2}$. First, the $\mathrm{Al}$ layer is removed from the corresponding MAX phase in $50 \%$ aqueous HF. The $\mathrm{f}-\mathrm{MXene}$ is then treated with an intercalant (urea is shown as an example) yielding intercalation compounds.

(b) XRD patterns of $\mathrm{f}-\mathrm{Ti}_{3} \mathrm{C}_{2}$ : (i) as received, before any treatment, (ii) after $\mathrm{HM}$ in DMF treatment, washed with DMF, (iii) after $\mathrm{HM}$ treatment, washed with ethanol and dried in different conditions. (c) Zoom-ins of $\mathbf{b}$ in the $5-12^{\circ} 2 \theta$ range showing $(0002)$ peaks.

Table 1 | Summary of the $c-L P s$, in $\AA$, values for non-intercalated $f-\mathrm{Ti}_{3} \mathrm{C}_{2}$ and $\mathrm{f}-\mathrm{Ti}_{3} \mathrm{C}_{2}$ treated with $\mathrm{HM}$ and $\mathrm{HM}$ in DMF.

\begin{tabular}{|c|c|c|c|c|c|}
\hline Intercalant & Non-intercalated & MD-non-intercalated & HM (XRD)^ & $\begin{array}{l}\text { HM (MD modelling } \\
\text { at } N / C \text { ratio } 0.375 \text { ) }\end{array}$ & HM in DMF (XRD)* \\
\hline Initial material $\dagger$ & $19.5 \pm 0.1$ & $19.85 \pm 0.01$ & $25.48 \pm 0.02$ & $25.31 \pm 0.04$ & $26.8 \pm 0.1$ \\
\hline After drying at $120^{\circ} \mathrm{C}$ & $19.5 \pm 0.1$ & NA & $20.6 \pm 0.3$ & NA & $26.0 \pm 0.2$ \\
\hline Vacuum drying at $200^{\circ} \mathrm{C}$ & $19.3 \pm 0.2$ & NA & $N / A$ & NA & $20.1 \pm 0.5$ \\
\hline
\end{tabular}

$(\mathrm{a} \times \mathrm{b} \times \mathrm{c})$ ) with $\mathrm{N}_{2} \mathrm{H}_{4}$ uniformly spaced between the MXene layers at different concentrations were constructed for MD studies. A detailed description of the simulations is provided in the Supplementary Methods. With no $\mathrm{N}_{2} \mathrm{H}_{4}$ molecules, the MDcomputed $c$-LP value is reasonably close to the experimental result (Table 1) and density functional theory (DFT)-calculated values ${ }^{17}$. When two $\mathrm{N}_{2} \mathrm{H}_{4}$ molecules are introduced (one into each interlayer space), the $c$-LP sharply jumps to $24.93 \pm 0.01 \AA$ (Fig. 3a). Further increase of the number of $\mathrm{N}_{2} \mathrm{H}_{4}$ molecules results in only slightly changed c-LPs (from 24.93 to $25.31 \AA$ ), corresponding to $\mathrm{N}_{2} \mathrm{H}_{4}$ monolayer formation (Fig. 3a) within the widened interlayer MXene space. With six $\mathrm{N}_{2} \mathrm{H}_{4}$ molecules per supercell (three inside each interlayer space as shown in Fig. 3b), the intercalant monolayer formation is complete and the introduction of the next pair of $\mathrm{N}_{2} \mathrm{H}_{4}$ molecules results in a second sharp increase of $c$-LP from $25.31 \pm 0.04 \AA$ (six $\mathrm{N}_{2} \mathrm{H}_{4}$ molecules) to $27.28 \pm 0.03 \AA$ (eight $\mathrm{N}_{2} \mathrm{H}_{4}$ molecules) as shown in Fig. 3a, which is an evidence for the onset for the formation of a second intercalant layer (see also MD snapshot in Supplementary Fig. S4a).

The experimental $c$-LP value for $\mathrm{N}_{2} \mathrm{H}_{4}$-intercalated f-MXene $(c=25.48 \AA$, Table 1$)$ corresponds to an MD-derived N/C ratio $\sim 0.39$ (Fig. 3a), that is, to the formation of a nearly complete monolayer of $\mathrm{N}_{2} \mathrm{H}_{4}$ molecules in each MXene interlayer space. The N/C ratio, determined by XPS for the HM-intercalated MXene dried at room temperature, is 0.37 , in very good agreement with the value deduced from the MD simulations 

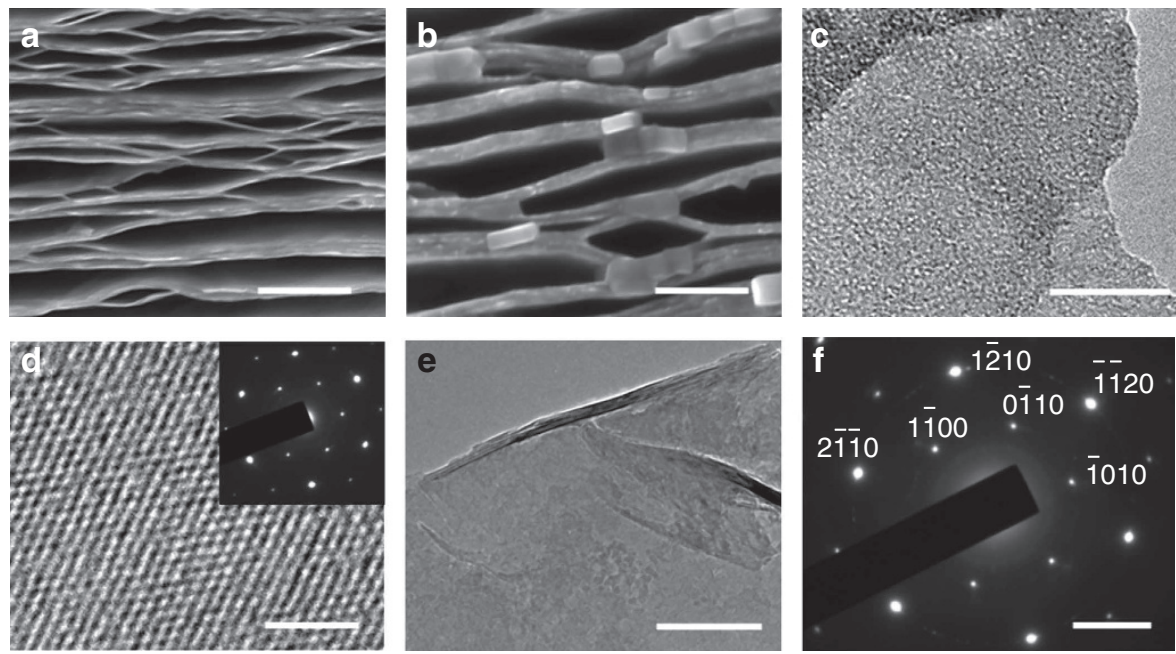

Figure 2 | Morphology characterization. (a,b) SEM images before (a) and after (b) intercalation of $\mathrm{f}-\mathrm{Ti}_{3} \mathrm{C}_{2}$ with $\mathrm{HM}$ and DMF $\left(24 \mathrm{~h}\right.$ at $\left.80^{\circ} \mathrm{C}\right)$, respectively. (c,d) TEM (c) and high-resolution electron microscopy (d) images (inset shows selected area electron diffraction (SAED) pattern) before intercalation. $(\mathbf{e}, \mathbf{f})$ TEM image (e) and SAED pattern (f) of intercalated $\mathrm{f}-\mathrm{Ti}_{3} \mathrm{C}_{2}$. Scale bars, $200 \mathrm{~nm}$ in $\mathbf{a}, \mathbf{b} ; 10 \mathrm{~nm}$ in $\mathbf{c} ; 2 \mathrm{~nm}$ in $\mathbf{d} ; 40 \mathrm{~nm}$ in $\mathbf{e}$; and $4 \mathrm{~nm}{ }^{-1}$ in $\mathbf{f}$.
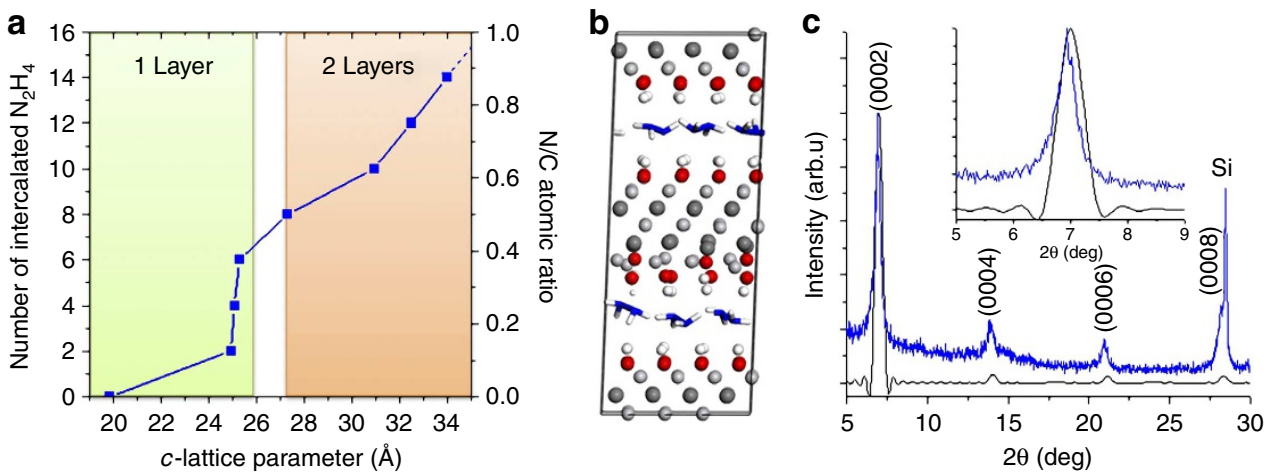

Figure 3 | Molecular dynamic simulations of $\mathrm{OH}$-terminated $\mathrm{Ti}_{\mathbf{3}} \mathbf{C}_{\mathbf{2}}$ intercalated with hydrazine. (a) Change in $\mathrm{f}-\mathrm{MXene} \mathrm{c}-\mathrm{LP}$ as a function of the number of $\mathrm{N}_{2} \mathrm{H}_{4}$ intercalated molecules. As the latter is increased, first a monolayer of $\mathrm{N}_{2} \mathrm{H}_{4}$ molecules is formed, corresponding to the $\mathrm{N} / \mathrm{C}$ ratio $\sim 0.4$ $(c=25-26 \AA)$. Further increase in the number of $\mathrm{N}_{2} \mathrm{H}_{4}$-intercalated molecules results in the onset of the second layer formation, which is not complete up to the maximum $\mathrm{N} / \mathrm{C}$ ratio employed in the simulations $(\mathrm{N} / \mathrm{C}=0.875)$. (b) Molecular dynamic snapshot of hydrazine intercalated $\mathrm{MXene}$ for $\mathrm{N} / \mathrm{C}$ ratio 0.375 (six $\mathrm{N}_{2} \mathrm{H}_{4}$ per a $4 \times 2 \times 1 \mathrm{MXene}$ supercell) showing a nearly complete $\mathrm{N}_{2} \mathrm{H}_{4}$ monolayer. For colour coding of the elements, please see Fig. 1a.

(c) Comparison of simulated (black) and experimental (blue) XRD patterns of $\mathrm{N}_{2} \mathrm{H}_{4}$ intercalated $\mathrm{OH}$-terminated $\mathrm{Ti}_{3} \mathrm{C}_{2}$.

$(\sim 0.4)$ for the situation with a nearly complete monolayer of $\mathrm{N}_{2} \mathrm{H}_{4}$ molecules (Figs 3a,b). Furthermore, the computed XRD pattern for the system of this composition is close to the one measured experimentally (Fig. 3c).

Delamination of MXene. We also tried to intercalate thiophene, ethanol, acetone, tetrahydrofuran, formaldehyde, chloroform, toluene, hexane, DMF, DMSO and urea into $\mathrm{f}-\mathrm{Ti}_{3} \mathrm{C}_{2}$ at room temperature. Of these, only DMSO and urea resulted in an increase in the $c$-LPs from $19.5 \pm 0.1 \AA$ to $35.04 \pm 0.02 \AA$ and $25.00 \pm 0.02 \AA$, respectively (Supplementary Fig. S5). It follows that DMF only intercalates into $\mathrm{f}-\mathrm{Ti}_{3} \mathrm{C}_{2}$ in the presence of $\mathrm{HM}$. Coincidentally or not, of the aforementioned list of organic compounds, only DMSO and urea intercalate kaolinite ${ }^{27,30}$.

XRD patterns, taken 3 weeks after the initial DMSO intercalation (Supplementary Fig. S5-ii, red curve), showed an even larger downshift of the (0002) peak positions corresponding to a $c$-LP of $44.8 \pm 0.1 \AA$. Based upon this result, combined with the observation that DMSO-intercalated f-MXene powders are highly hygroscopic and become increasingly wet when stored in air over a few weeks, it is reasonable to assume that, over time, co-intercalation or capillary condensation of water from ambient air into the interlayer space occurred.

This discovery, in turn, was exploited to fully exfoliate-what we term delaminate herein (see Supplementary Fig. S6 for schematic) $-\mathrm{f}-\mathrm{Ti}_{3} \mathrm{C}_{2}$ sheets. After a weak sonication of DMSOintercalated f-MXene dispersed in deionized water, fully delaminated-that we denote as $\mathrm{d}-\mathrm{Ti}_{3} \mathrm{C}_{2}$-flakes were obtained. After removal of large particles by centrifuging, the resulting aqueous colloidal solutions of d-MXene flakes were quite stable. The majority of flakes were small with a relatively narrow size distribution (Fig. 4a). The colloidal state of d-MXene flakes in aqueous solutions was also confirmed by the observation of the Tyndall scattering effect when passing a red laser beam through the solution (inset Fig. 4a). SEM images clearly showed thin, electron-beam transparent, single MXene flakes precipitated from a drop of colloidal $\mathrm{d}-\mathrm{Ti}_{3} \mathrm{C}_{2}$ solution placed on a porous alumina membrane surface (Fig. $4 \mathrm{~b}$ ).

Binder-free MXene 'paper' (inset Fig. 4d) was produced by filtering the aforementioned colloidal solution through a membrane. XRD patterns of the resulting 'paper' (Fig. 4c) 

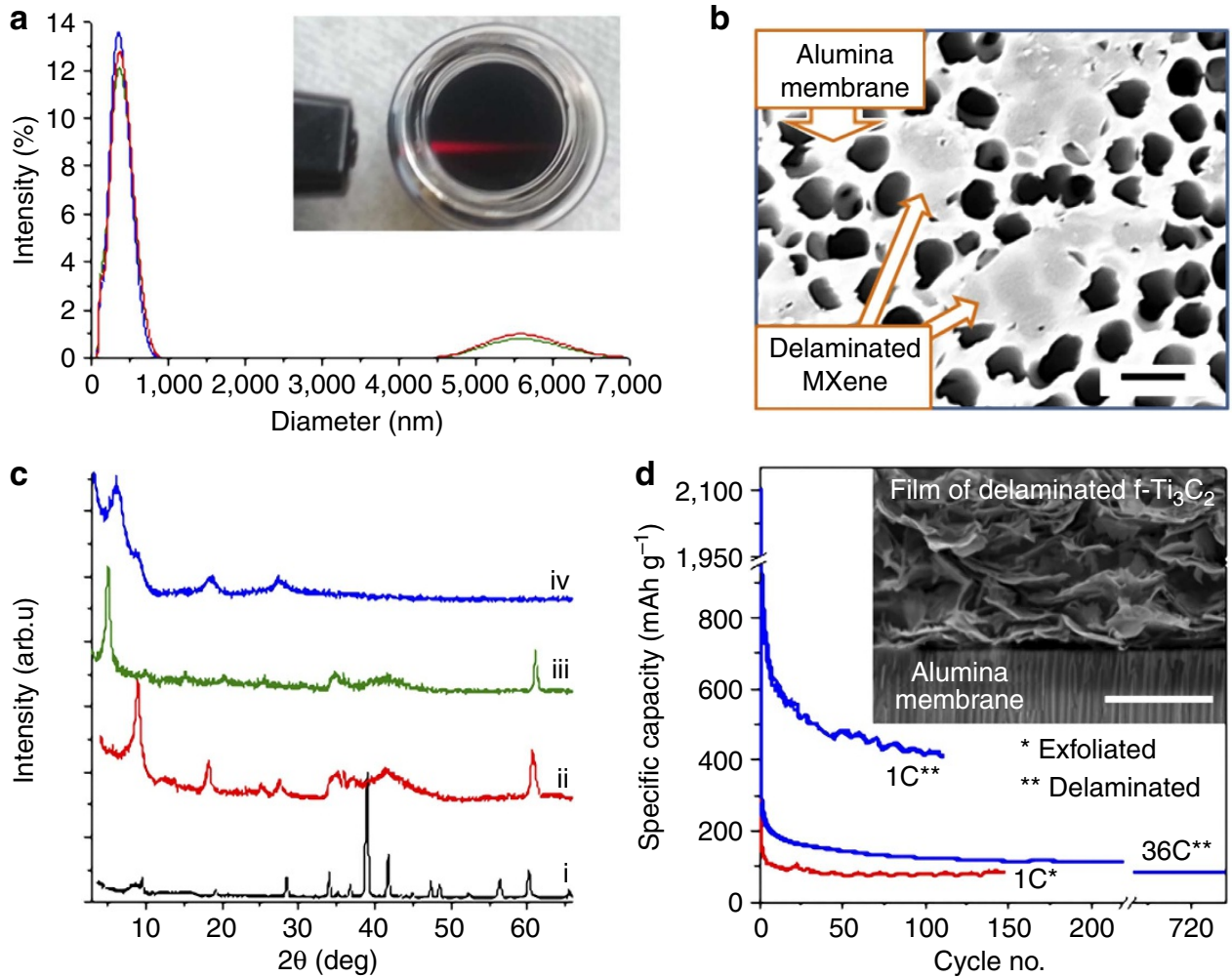

Figure 4 | Delaminated $\mathbf{f}-\mathrm{Ti}_{\mathbf{3}} \mathbf{C}_{\mathbf{2}}$ and its properties. (a) Particle size distribution in aqueous colloidal solution; inset shows Tyndall scattering effect in the solution. (b) SEM images of $\mathrm{f}-\mathrm{Ti}_{3} \mathrm{C}_{2}$ flakes on an alumina membrane. (c) XRD patterns of (i) $\mathrm{Ti}_{3} \mathrm{AlC}_{2}$, (ii) exfoliated, (iii) DMSO intercalated and (iv) delaminated $\mathrm{Ti}_{3} \mathrm{C}_{2}$. Note the disappearance of the non-basal peaks at $\sim 60^{\circ}$ in iv. (d) Comparison of the performance of exfoliated and delaminated $\mathrm{f}-\mathrm{Ti}_{3} \mathrm{C}_{2}$ as anode material in Li-ion batteries. Inset shows SEM image of an additive-free film of delaminated $\mathrm{f}-\mathrm{Ti}_{3} \mathrm{C}_{2}$ filtered through the membrane.

Scale bars, $0.4 \mu \mathrm{m}$ in $\mathbf{b} ; 4 \mu \mathrm{m}$ in inset $\mathbf{d}$.

clearly showed that the non-basal peaks at $\sim 60^{\circ} 2 \theta$ vanished after delamination. This result provides compelling evidence for the loss of order along all, but [0001] and consequently, full delamination.

Energy storage applications of delaminated MXene. A recent computational study ${ }^{25}$ concluded that $\mathrm{d}-\mathrm{Ti}_{3} \mathrm{C}_{2}$ layers would be attractive for Li-ion battery anodes. To date, our Li-ion work was carried out on stacked multilayer particles ${ }^{23,24}$. The breakthrough presented herein, however, allowed us to measure Li-ion uptake on $\mathrm{d}-\mathrm{Ti}_{3} \mathrm{C}_{2}$ 'paper'. As shown in Fig. $4 \mathrm{~d}$, the capacity of the latter is a factor of 4 higher than that of as-synthesized f-MXene.

The 'paper' showed a capacity of $410 \mathrm{~mA} \mathrm{~h}^{-1}$ at a $1 \mathrm{C}$ cycling rate and $110 \mathrm{mAhg}^{-1}$ at $36 \mathrm{C}$ (Fig. 4d). As shown in Supplementary Fig. S7, the $410 \mathrm{~mA} \mathrm{hg}^{-1}$ represents three $\mathrm{Li}$ per $\mathrm{Ti}_{3} \mathrm{C}_{2}(\mathrm{OH})_{2}$. The capacity obtained at $1 \mathrm{C}$ was higher than the maximum theoretical capacity of $\mathrm{f}-\mathrm{Ti}_{3} \mathrm{C}_{2}$ MXene predicted by Tang et al. ${ }^{25}$ using DFT $\left(320 \mathrm{mAhg}^{-1}\right)$, although the as-delaminated d-MXenes have $\mathrm{OH}$ and $\mathrm{F}$ on the surface that theoratically reduce the reversible capacity. The reason for this mismatch is unclear at this time. However, a similar phenomenon observed on other nano-structured electrodes was explained by assuming the excess capacity stored in a unique reversible solid electrolyte interphase ${ }^{31-35}$. More work is ongoing to understand the lithiation and delithiation mechanisms of d-MXenes, in addition to further optimization of their performance. The results shown in Fig. $4 \mathrm{~d}$ are noteworthy as they demonstrate Li capacities at $1 \mathrm{C}$ that are better than graphite, used in commercial LIBs. For example, at $280 \mathrm{~mA} \mathrm{hg}^{-1}$, graphite's capacity at $1 \mathrm{C}$ is $\approx 75 \%$ of its theoretical capacity ${ }^{36}$. Similarly, lithium titanate is known for its capability to handle high cycling rates. For example, at $1 \mathrm{C}$, the capacity of $\mathrm{Li}_{4} \mathrm{Ti}_{5} \mathrm{O}_{12}$ was $<170 \mathrm{~mA} \mathrm{~h}^{-1}$ (ref. 37).

\section{Discussion}

Based on the results presented above, it is obvious that in ways reminiscent of graphite and clays, f-MXenes can be intercalated by a variety of organic molecules. This discovery can lead to the intercalation of a broad range of organics and salts, as well as provide routes to carry out complex chemical reactions-such as catalysis and polymerization (similar to intercalated graphite) ${ }^{38}$ within the f-MXene interlayer galleries. Furthermore, the intercalation of DMSO between $\mathrm{f}-\mathrm{Ti}_{3} \mathrm{C}_{2}$ sheets, followed by sonication in water, resulted in their delamination into separate sheets in an aqueous suspension from which a $\mathrm{Ti}_{3} \mathrm{C}_{2}$-based 'paper' was made. The Li uptake of the latter was significantly higher than its non-delaminated counterpart.

The results obtained herein are of both fundamental and practical importance. On the fundamental side, they establish $\mathrm{f}-\mathrm{MXenes}$ as full-fledged members of the growing family of $2 \mathrm{D}$ materials, with all the potential that such materials provide. It is crucial to note that in sharp contrast to most $2 \mathrm{D}$ materials made to date-in which weakly bonded layers were exfoliated/ delaminated-the work presented here was carried out on the MAX phases, that are layered, but in which the bonding is exceptionally strong. Said otherwise, the world of 2D solids need not be restricted to layered solids with weak bonds, which is truly paradigm shifting. From a practical point of view, our results 
open avenues for the development of numerous applications in composites, catalysis, sorption and energy storage systems.

\begin{abstract}
Methods
Intercalation of f-MXene. To intercalate f-MXene with HM, the f-MXene powders were suspended either in HM or a 1:3 mixture of HM and DMF, and mag netically stirred for $24 \mathrm{~h}$, either at room temperature (RT) or at $80^{\circ} \mathrm{C}$. In all cases, the weight ratio of HM:MXene was 10:1. When the treatment involved only HM, the suspensions were filtered and washed with ethanol. In case of intercalation with HM/DMF mixture, DMF was used for washing instead of ethanol. The powders were then dried in a desiccator under vacuum $(<10 \mathrm{Torr})$ at $\mathrm{RT}$ for $24 \mathrm{~h}$ or in the vacuum oven $\left(\sim 10^{-2}\right.$ Torr $)$ at $120^{\circ} \mathrm{C}$ for $24 \mathrm{~h}$.

Intercalation of other organic compounds was attempted. Those included DMSO, urea, DMF, acetone, ethyl alcohol, tetrahydrofuran, chloroform, toluene, thiophene and formaldehyde. In all cases, the intercalation procedure was the same: (i) $0.3 \mathrm{~g}$ of $\mathrm{f}-\mathrm{Ti}_{3} \mathrm{C}_{2}$ were mixed with $5 \mathrm{ml}$ of each of the organic compounds listed above (excluding urea), then magnetically stirred for $24 \mathrm{~h}$ at RT; (ii) in the case of urea, $5 \mathrm{ml}$ of $50 \mathrm{wt} . \%$ aqueous solution of urea was added to $0.3 \mathrm{~g}$ of $\mathrm{f}-\mathrm{Ti}_{3} \mathrm{C}_{2}$ and stirred for $24 \mathrm{~h}$ at $60^{\circ} \mathrm{C}$. Later, the resulting colloidal solutions were filtered and dried in a desiccator under vacuum $(<10$ Torr) at RT. A detailed experimental section (materials used, techniques of material preparation and de-intercalation of MXenes) can be found in the Supplementary Methods.
\end{abstract}

De-intercalation of MXene. To de-intercalate hydrazine/DMF, the intercalated MXene powder was carefully weighed, placed in a graphite crucible and outgassed at $\mathrm{RT}$ in vacuum $\left(\sim 10^{-6}\right.$ Torr $)$ for $24 \mathrm{~h}$. While under vacuum, the powder was then heated to $200^{\circ} \mathrm{C}$ at $10^{\circ} \mathrm{C} \mathrm{min}^{-1}$, held at this temperature for $72 \mathrm{~h}$ and cooled to RT. The powder remained under vacuum for another $48 \mathrm{~h}$ before it was retrieved. Between its removal from the furnace and re-weighing, the sample was exposed to ambient air for $\sim 3 \mathrm{~min}$.

Delamination of MXene. For delamination, DMSO was used. After stirring of $\mathrm{f}-\mathrm{Ti}_{3} \mathrm{C}_{2}$ with DMSO for $18 \mathrm{~h}$ at room temperature, the colloidal suspension was centrifuged to separate the intercalated powder from the liquid DMSO. After decantation of the supernatant, deionized water was added to the residue in a weight ratio of f-MXene to water of 1:500. After bath sonication of the suspension for $6 \mathrm{~h}$, centrifuging was carried out and the supernatant was filtered using a porous anodic aluminium oxide membrane filter $(47 \mathrm{~mm}$ diameter, $0.2 \mu \mathrm{m}$ pore size, Whatman Anodisc, Maidstone, UK) and dried in the oven at $\sim 70^{\circ} \mathrm{C}$ overnight, resulting in d-MXene 'paper' that detach easily from the membrane.

Preparation of pressed MXene discs. The non-intercalated and intercalated MXene powders were cold pressed under a load corresponding to a stress of $0.8 \mathrm{GPa}$ using a manual hydraulic pellet press (Carver, Model 4350.L, Carver Inc., Wabash, USA). The resulting discs were $12.5 \mathrm{~mm}$ in diameter and $228-432 \mu \mathrm{m}$ thick.

Physical characterization. XRD patterns were recorded with a powder diffractometer (Siemens D500, Germany) using $\mathrm{Cu} \mathrm{K}$ r radiation $(\lambda \sim 1.54 \AA)$ with $0.02^{\circ} 2 \theta$ steps and $1 \mathrm{~s}$ dwelling time. A SEM (Zeiss Supra 50VP, Germany) was used to obtain images of the particles. The $2 \mathrm{D}$ sheets were also imaged with a TEM (JEOL JEM-2100, Japan) using an accelerating voltage of $200 \mathrm{kV}$. The TEM samples were prepared by suspending the powders in isopropanol, sonicating for $1 \mathrm{~min}$ and drying a drop of the mixture transferred on a 200 mesh lacey-carbon-coated copper grid. An XPS (PHI 5000, ULVAC-PHI Inc., Japan) was used to analyse the surface elemental composition of the powders before and after intercalation. The electrical resistance of cold-pressed discs of non-intercalated and intercalated MXenes was measured using a four-probe technique (Cascade Probe Station CPS-1303-24 with 4-point probe head Alessi C4S-57, Cascade Microtech Inc., Beaverton, USA). More information on techniques used for material characterization can be found in the Supplementary Methods.

Electrochemical characterization. Electrochemical measurements were carried out using coin cells. The lithium-ion batteries' cyclabilities were studied using a galvanostatic charge-discharge cycling (GV) and a battery cycler (Arbin BT-2143$11 \mathrm{U}$, College Station, TX, USA). In GV tests, the batteries were charged and discharged between 0 and $2.5 \mathrm{~V}$ versus $\mathrm{Li} / \mathrm{Li}^{+}$with an imposed current, while the potential change was measured. From this measurement, the specific capacities were calculated for each cycle as $Q=(I \times t) / m$; where $Q$ is the specific capacitance (in $\mathrm{mA} \mathrm{h}^{-1}$ ), $I$ is the current (in $\mathrm{mA}$ ), $t$ is the time (in h) and $m$ is the mass of active material (in g). Note that for the f-MXene-based electrode before delamination, only the f-MXene mass, without that of the additives, was taken into account. For the delaminated d-MXene, as there were no additives, the mass considered is that of the d-MXene paper.

Preparation of lithium coin cells. The exfoliated, but un-delaminated, $\mathrm{f}-\mathrm{Ti}_{3} \mathrm{C}_{2}$ was made into an anode by mixing it with $10 \mathrm{wt} . \%$ poly(1,1-difluoroethylene) dissolved in 1-methyl-2-pyrrolidinone. The mixture was spread on $\mathrm{Cu}$ foil using a doctor blade, and dried at $140^{\circ} \mathrm{C}$ for $12 \mathrm{~h}$ under vacuum $(<10$ Torr $)$. To make the $\mathrm{d}-\mathrm{Ti}_{3} \mathrm{C}_{2}$ anode, dried 'paper' $\left(3 \mathrm{mg} \mathrm{cm}{ }^{-2}\right)$ without any additives was used. Stainless steel coin cells, type CR-2016 (MTI, Richmond, CA, USA) were assembled with the $\mathrm{f}$ - or d-MXene as the positive electrode and Li metal foil as a counter electrode. A borosilicate glass fibre (Whatman GF/A, Buckinghamshire, UK) separated them. The electrolyte was a $1 \mathrm{M} \mathrm{LiPF}_{6}$ solution in a 1:1 by weight mixture of ethylene carbonate and diethyl carbonate. The coin cells were assembled using crimping machine (MTI EQ-MSK-110, Richmond, CA, USA) in an Ar-filled glove box, with less than 1 p.p.m. of $\mathrm{O}_{2}$ or $\mathrm{H}_{2} \mathrm{O}$.

MD simulations. MD simulations were performed using Forcite module in Materials Studio suite (Accelrys). Owing to the unusual composition of the system, including $\mathrm{C}, \mathrm{Ti}, \mathrm{O}, \mathrm{N}$ and $\mathrm{H}$, the Universal Force Field ${ }^{39}$ was used to calculate the system's energy (see Supplementary Methods for details). Before simulations, $4 \times 2 \times 1(a \times b \times c)$ OH-terminated $\mathrm{Ti}_{3} \mathrm{C}_{2}$ periodic supercells with different numbers of $\mathrm{N}_{2} \mathrm{H}_{4}$ molecules were constructed using the unit cell structure of $\mathrm{f}-\mathrm{Ti}_{3} \mathrm{C}_{2}$ from previous DFT simulations ${ }^{17}$. The supercells, subjected to isostatic external pressure of $0.1 \mathrm{MPa}(1 \mathrm{~atm})$, were first relaxed by geometry optimization (convergence tolerance: energy $=0.02 \mathrm{cal} \mathrm{mol}^{-1}$, force $=1 \mathrm{cal} \mathrm{mol}^{-1} \AA^{-1}$, stress $=1 \mathrm{MPa}$ and displacement $=0.00001 \AA$ ) with no constraints allowing for all atom positions in the cell, as well as the cell parameters, to be optimized. Charge distribution was calculated using the QEq method (initial charge $=0$, maximum iterations $=100$, convergence limit $=0.0005 \bar{e}$ and parameter set $=$ QEq_charged 1.1 .

Once optimized, the supercells were used as initial structures in the MD runs. Constant number of particles N, pressure $\mathrm{P}$, and temperature T (NPT) ensemble MD was performed at $298 \mathrm{~K}$ (Nose thermostat with $\mathrm{Q}$ ratio $=1.0$ ) with random initial velocities and 0.1 MPa external isostatic pressure (Berendsen barostat with decay constant $=0.1 \mathrm{ps})$ for $300 \mathrm{ps}$ with $1 \mathrm{fs}$ steps $(300,000$ steps in total). Snapshots of the system were saved every 3,000 MD steps (100 snapshots in total) of which only the last 50 snapshots were used for analysis. This procedure allowed for $>100 \mathrm{ps}$ in the beginning of each run for thermal equilibration of the system with the analysis being performed on the part of MD trajectory corresponding to a system in an equilibrium state (Supplementary Fig. S4b,c), where all energy terms and density of the system remain nearly constant. No constrains on atom positions or cell parameters were applied during the MD run. During both the geometry optimization step and the MD run, the electrostatic interactions were summed up using Ewald scheme and the van der Waals interactions were summed up using the atom-based scheme.

\section{References}

1. Dresselhaus, M. S. \& Dresselhaus, G. Intercalation compounds of graphite. $A d v$. Phys. 30, 139-326 (1981).

2. Pinnavaia, T. J. Intercalated clay catalysts. Science 220, 365-371 (1983).

3. Ogawa, M. \& Kuroda, K. Photofunctions of intercalation compounds. Chem. Rev. 95, 399-438 (1995).

4. Podsiadlo, P. et al. Ultrastrong and stiff layered polymer nanocomposites. Science 318, 80-83 (2007).

5. Ma, R. Z. \& Sasaki, T. Nanosheets of oxides and hydroxides: ultimate $2 \mathrm{D}$ charge-bearing functional crystallites. Adv. Mater. 22, 5082-5104 (2010).

6. McKelvy, M. J. \& Glaunsinger, W. S. Molecular intercalation reactions in lamellar compounds. Annu. Rev. Mater. Sci. 41, 497-523 (1990).

7. Novoselov, K. S. et al. Two-dimensional atomic crystals. Proc. Natl Acad. Sci. USA 102, 10451-10453 (2005).

8. Stoller, M. D., Park, S., Zhu, Y., An, J. \& Ruoff, R. S. Graphene-based ultracapacitors. Nano Lett. 8, 3498-3502 (2008).

9. Shih, C. J. et al. Bi- and trilayer graphene solutions. Nat. Nanotech. 6, 439-445 (2011).

10. Eda, G. \& Chhowalla, M. Chemically derived graphene oxide: towards largearea thin-film electronics and optoelectronics. Adv. Mater. 22, 2392-2415 (2010).

11. Kumar, A. et al. Direct synthesis of lithium-intercalated graphene for electrochemical energy storage application. ACS Nano. 5, 4345-4349 (2011).

12. Coleman, J. N. et al. Two-dimensional nanosheets produced by liquid exfoliation of layered materials. Science 331, 568-571 (2011).

13. Zhang, Z., Liu, X., Yakobson, B. I. \& Guo, W. Two-dimensional tetragonal TiC monolayer sheet and nanoribbons. J. Am. Chem. Soc. 134, 19326-19329 (2012).

14. Terrones, M. Materials science: nanotubes unzipped. Nature 458, 845-846 (2009).

15. Eda, G. et al. Photoluminescence from chemically exfoliated $\mathrm{MoS}_{2}$. Nano Lett. 11, 5111-5116 (2011).

16. Barsoum, M. W. The $\mathrm{M}_{\mathrm{N}+1} \mathrm{AX}_{\mathrm{N}}$ phases: a new class of solids; thermodynamically stable nanolaminates. Prog. Solid State Chem. 28, 201-281 (2000).

17. Naguib, M. et al. Two-dimensional nanocrystals produced by exfoliation of $\mathrm{Ti}_{3} \mathrm{AlC}_{2}$. Adv. Mater. 23, 4248-4253 (2011) 
18. Naguib, M. et al. Two-dimensional transition metal carbides. ACS Nano. 6, 1322-1331 (2012)

19. Viculis, L. M., Mack, J. J. \& Kaner, R. B. A chemical route to carbon nanoscrolls. Science 299, 1361-1361 (2003).

20. Savoskin, M. V. et al. Carbon nanoscrolls produced from acceptor-type graphite intercalation compounds. Carbon 45, 2797-2800 (2007).

21. Enyashin, A. N. \& Ivanovskii, A. L. Atomic structure, comparative stability and electronic properties of hydroxylated $\mathrm{Ti}_{2} \mathrm{C}$ and $\mathrm{Ti}_{3} \mathrm{C}_{2}$ nanotubes. Comput. Theor. Chem. 989, 27-32 (2012).

22. Kurtoglu, M., Naguib, M., Gogotsi, Y. \& Barsoum, M. W. First principles study of two-dimensional early transition metal carbides. MRS Commun. 2, 133-137 (2012).

23. Naguib, M. et al. MXene: a promising transition metal carbide anode for lithium-ion batteries. Electrochem. Commun. 16, 61-64 (2012).

24. Come, J. et al. A non-aqueous asymmetric cell with a $\mathrm{Ti}_{2} \mathrm{C}$-based twodimensional negative electrode. J. Electrochem. Soc. 159, A1368-A1373 (2012).

25. Tang, Q., Zhou, Z. \& Shen, P. W. Are MXenes promising anode materials for Li ion batteries? Computational studies on electronic properties and $\mathrm{Li}$ storage capability of $\mathrm{Ti}_{3} \mathrm{C}_{2}$ and $\mathrm{Ti}_{3} \mathrm{C}_{2} \mathrm{X}_{2}(\mathrm{X}=\mathrm{F}, \mathrm{OH})$ monolayer. J. Am. Chem. Soc. 134, 16909-16916 (2012).

26. Park, S. et al. Colloidal suspensions of highly reduced graphene oxide in a wide variety of organic solvents. Nano Lett. 9, 1593-1597 (2009).

27. Ledoux, R. L. \& White, J. L. Infrared studies of hydrogen bonding interaction between kaolinite surfaces and intercalated potassium acetate, hydrazine, formamide, and urea. J. Colloid Interf. Sci. 21, 127-152 (1966).

28. Frost, R. L., Kristof, J., Horvath, E., Martens, W. N. \& Kloprogge, J. T. Complexity of intercalation of hydrazine into kaolinite - A controlled rate thermal analysis and DRIFT spectroscopic study. J. Colloid Interf. Sci. 251, 350-359 (2002).

29. Deng, Y. J., Dixon, J. B. \& White, G. N. Molecular configurations and orientations of hydrazine between structural layers of kaolinite. J. Colloid Interf. Sci. 257, 208-227 (2003).

30. Olejnik, S., Aylmore, L. A. G., Posner, A. M. \& Quirk, J. P. Infrared spectra of kaolin mineral-dimethyl sulfoxide complexes. J. Phys. Chem. 72, 241-249 (1968).

31. Su, L. W., Zhou, Z. \& Shen, P. W. Ni/C hierarchical nanostructures with Ni nanoparticles highly dispersed in $\mathrm{N}$-containing carbon nanosheets: origin of $\mathrm{Li}$ storage capacity. J. Phys. Chem. C 116, 23974-23980 (2012).

32. Su, L., Zhou, Z. \& Shen, P. Core-shell Fe@Fe ${ }_{3} \mathrm{C} / \mathrm{C}$ nanocomposites as anode materials for Li ion batteries. Electrochim. Acta. 87, 180-185 (2013).

33. Su, L. et al. $\mathrm{CoCO}_{3}$ submicrocube/graphene composites with high lithium storage capability. Nano Energy, http://dx.doi.org/10.1016/j.nanoen.2012.09.012.

34. Laruelle, S. et al. On the origin of the extra electrochemical capacity displayed by $\mathrm{MO} / \mathrm{Li}$ cells at low potential. J. Electrochem. Soc. 149, A627-A634 (2002).
35. Guo, B. et al. Electrochemically fabricated polypyrrole-cobalt-oxygen coordination complex as high-performance lithium-storage materials. Chem. Eur. J. 17, 14878-14884 (2011).

36. Wang, X.-L. et al. Visualizing the chemistry and structure dynamics in lithiumion batteries by in-situ neutron diffraction. Sci. Rep. 2, 1-7 (2012).

37. Nakahara, K., Nakajima, R., Matsushima, T. \& Majima, H. Preparation of particulate $\mathrm{Li}_{4} \mathrm{Ti}_{5} \mathrm{O}_{12}$ having excellent characteristics as an electrode active material for power storage cells. J. Power Sources 117, 131-136 (2003).

38. Shioyama, H. \& Akita, T. A new route to carbon nanotubes. Carbon 41, 179-181 (2003).

39. Rappe, A. K., Casewit, C. J., Colwell, K. S., Goddard, W. A. \& Skiff, W. M. UFF, a full periodic-table force-field for molecular mechanics and moleculardynamics simulations. J. Am. Chem. Soc. 114, 10024-10035 (1992).

\section{Acknowledgements}

We thank Maria Lukatskaya for an SEM image, Boris Dyatkin for help with sample preparation and BET analysis, Laura Allen for help in making the MXene paper and the Centralized Research Facility of Drexel University for providing access to XRD, XPS, SEM and TEM. This work was funded by the Assistant Secretary for Energy Efficiency and Renewable Energy, Office of Vehicle Technologies of the US. Department of Energy under Contract No. DE-AC02-05CH11231, Subcontract 6951370 under the Batteries for Advanced Transportation Technologies (BATT) Programme.

\section{Author contributions}

O.M. carried out all of the intercalation work and characterization by TEM and part of XRD analysis. M.N. carried out synthesis of the pure MAX phases and the MXenes, all of the delamination work and characterization by the XRD and SEM. Y.D. and M.N performed electrochemical measurements. V.N.M. performed the computational studies and overseen the experimental programme. Y.G. and M.W.B. conceived and directed the project. The manuscript was prepared by O.M., V.N.M., M.N., M.W.B. and Y.G. All authors discussed the results and commented on the manuscript.

\section{Additional information}

Supplementary Information accompanies this paper at http://www.nature.com/ naturecommunications

Competing financial interests: The authors declare no competing financial interests

Reprints and permission information is available online at http://npg.nature.com/ reprintsandpermissions/

How to cite this article: Mashtalir, O. et al. Intercalation and delamination of layered carbides and carbonitrides. Nat. Commun. 4:1716 doi: 10.1038/ncomms2664 (2013). 